\title{
Annotations
}

\section{High frequency positive pressure ventilation in neonates}

After a period of comparative stability, the clinician responsible for the care of the neonate in respiratory failure is faced with conflicting advice, not only on the settings he should be selecting on the ventilator, ${ }^{1}$ but also whether he should be considering an entirely different form of respiratory support. The aim of this annotation is to look critically at the information available in an attempt to identify what represents a useful clinical advance and what should still be considered experimental.

The recommendations of Reynolds ${ }^{2} 3$ that babies with respiratory distress syndrome should be ventilated at low respiratory rates (about 30/minute) and with a high inspiratory/expiratory ratio $(1: 1,2: 1)$ have been challenged for three main reasons ${ }^{4}$; firstly, the incidence of pneumothorax and bronchopulmonary dysplasia has remained high; secondly, the babies requiring respiratory support are now considerably less mature; ${ }^{5}$ and thirdly, there are now numerous ventilators available on the market specifically designed for infants, which perform far better than those available when Reynolds was carrying out his classic studies. There have been three main approaches to these challenges, all coming under the umbrella term 'high frequency ventilation' but representing completely different techniques. These are: high frequency positive pressure ventilation, high frequency jet ventilation, and high frequency oscillation.

\section{High frequency positive pressure ventilation}

During the last 10 years new ventilators have been developed that function adequately at rates of up to 120 /minute. ${ }^{6}$ There is now increasing evidence to suggest that arterial oxygenation is at least as good at $60 /$ minute as it is at $30 /$ minute, and that the higher rate is associated with a lower incidence of pneumothorax. ${ }^{78}$ Studies have also shown that active expiratory efforts generated by the baby against the inflation pressure (fighting the ventilator), a pattern that has been associated with a high incidence of pneumothorax, ${ }^{9}$ may often be eliminated by raising the ventilator rate to 100 or even 120 /minute..$^{10}$ This procedure is associated not only with an increase in carbon dioxide elimination, but often also with an improvement in arterial oxygenation, thereby avoiding the need for paralysis. There seems little benefit in raising the rate from $60-120 /$ minute if the baby is apnoeic or is breathing synchronously with the ventilator at the lower rate. ${ }^{1213}$ It is, however, important to ensure that at these higher rates expiratory time is at least as long as inspiration, otherwise there will be insufficient time for expiration to be completed, leading to alveolar over distension as a result of positive end expiratory pressure. ${ }^{1}$ This will not be apparent from measurements at the patient manifold, but may adversely effect cardiac output and, indeed, lead to pneumothoraces.

\section{High frequency jet ventilation}

This is the modification of a technique initially developed to provide respiratory support during bronchoscopy. Gas from a high pressure source is delivered in short bursts down a fine cannula, the tip of which is lying within the endotracheal tube and pointing down towards the periphery of the lung. ${ }^{14}$ These 'bullets' of gas entrain additional gas down the endotracheal tube. For most studies rates of $100-200 /$ minute have been selected, although the device has been used at rates as high as $400-600$ / minute. There have now been several studies showing that this is an effective form of ventilation, ${ }^{14-16}$ which may lead to improvements in blood gas tensions when satisfactory results are not being obtained by conventional techniques. Initial hopes were that this form of ventilation would lead to less long term respiratory disability, as it is often possible to achieve adequate blood gas tensions with lower peak inflation pressures. ${ }^{15}$ Unfortunately there has been a high incidence of damage to the trachea and large airways, ${ }^{17}$ sometimes occurring within comparatively few hours of starting treatment. It was originally considered that the damage resulted from poor humidification ${ }^{18}$; it now seems to be caused by direct trauma from the high velocity bullets as well. ${ }^{16}{ }^{17}$ For this reason high frequency jet ventilation is best reserved for times when 
conventional ventilation has failed and when respiratory support of this type will only be required for a few hours-for example, in babies with diaphragmatic hernias who have yet to undergo operation. There may also be a place for this technique in babies with pulmonary interstitial emphysema who are proving difficult to ventilate conventionally. ${ }^{19}$

High frequency flow interruptors can best be classified as a subgroup of high frequency jet ventilators but differ in that the intermittent high pressure gas source is fed into a continuous positive airway pressure circuit immediately opposite the endotracheal tube connector. The pressure is released into the circuit either through a tube drilled across a rotating sphere mounted in a block ${ }^{20}$ or across a shutter system. These devices seem to produce less large airway damage, can be used at frequencies of up to $20 \mathrm{~Hz}(1200 /$ minute $)$, and also lead to improvements in infants with pulmonary interstitial emphysema. ${ }^{21}$

\section{High frequency oscillation}

In this technique a sinusoidal volume generator feeds into a continuous positive airway pressure circuit close to the patient manifold. This produces a different wave form from the grossly distorted 'square wave' pattern produced by all the high frequency jet ventilators. The generator is either a piston, bellows, or a loud speaker driven by a synewave generator and audio amplifier. Much of the oscillating volume is lost into the continuous positive airway pressure circuit and the amount entering and leaving the endotracheal tube depends on a number of factors, including the comparative impedence of the baby's respiratory tract and the continuous positive airway pressure circuit, and the frequency selected. The high frequency oscillation may also be given at the same time as conventional ventilation. It has generally been accepted that this form of ventilation provides tidal exchange that is considerably less than the baby's anatomical dead space. ${ }^{14}$ Experiments in animals and also in human adult volunteers have indicated that there are optimal frequencies at which the tidal exchange that is induced increases considerably. ${ }^{14}$ These frequencies are thought to represent those that most closely match the natural resonance frequency of the respiratory system. A recent study has indicated ${ }^{22}$ that even in the respiratory distress syndrome there is often a critical frequency (usually in the range of $12-24 \mathrm{~Hz}$ ) at which even with oscillating pressures of less than $15 \mathrm{~cm}$ of water, tidal volumes in excess of anatomical dead space can be obtained.

All the studies to date have shown that high frequency oscillation improves elimination of carbon dioxide, possibly by direct alveolar ventilation and facilitated diffusion - that is, an exaggeration of the normal gas mixing process in the lung, and helped by oscillations between different parts of the lung. ${ }^{23}$ The effects of high frequency oscillation on oxygenation have been less consistent. ${ }^{14}$ It may be that this is determined more by the mean alveolar pressure and the presence of adequate carbon dioxide clearance than by improved delivery of oxygen to the terminal air sacks. It is certainly current practice to provide high continuous positive airway pressures, often in excess of $15 \mathrm{~cm}$ of water, during periods of high frequency oscillation. There is also evidence that high frequency oscillation can itself lead to over distension of the terminal air sacks as gas pushed into the air has insufficient time to escape. A recent study has shown that alveolar postive end expiratory pressure in excess of $4 \mathrm{~cm}$ of water is a common finding when the oscillating frequency exceeds $20 \mathrm{~Hz}$ (1200/minute).${ }^{24}$ Although alveolar positive end expiratory pressure may lead to increased oxygen uptake, there is evidence that high frequency oscillation can have adverse effects on cardiac output ${ }^{25}$ and there is certainly a high incidence of pneumothorax associated with this form of ventilation. Perhaps the most worrying aspect is that the extent of the positive end expiratory pressure will be determined by the wave form produced by the device, the size of the endotracheal tube, whether there are any secretions present, the mechanical characteristics of the lungs and, probably, the extent to which the disease is homogeneous throughout the lungs. A recent study has shown that it is possible to measure the degree of alveolar positive end expiratory pressure produced by occluding the airway and measuring the back pressure ${ }^{26}$ providing there is an airtight seal between the endotracheal tube and the trachea. It may be that this measurement will be an essential part of ventilatory management when high frequency oscillation is used more extensively.

\section{Conclusion}

There are now a numbèr of studies indicating that ventilatory rates of $60 /$ minute with inspiratory times of less than 0.5 seconds produce good oxygenation, better carbon dioxide clearance, and have a lower incidence of pneumothorax than lower rates and inspiratory times of one second or greater. Babies who are fighting the ventilator at 60 /minute can often be helped by increasing the respiratory rate in an attempt to produce a state in which the baby is breathing synchronously with the ventilator, taking care to ensure that expiration is at least as long as 
inspiration to prevent alveolar positive end expiratory pressure. High frequency jet ventilation is effective, but produces too many tracheal lesions to be acceptable for more than short term treatment. Although high frequency oscillation is an effective way of eliminating carbon dioxide, oxygenation is not always improved and there are potential hazards. It should still be considered as an experimental treatment that has not yet earned its place as a routine tool in clinical management.

\section{References}

${ }^{1}$ Ramsden CA, Reynolds EOR. Ventilator settings for newborn infants. Controversy and comment. Arch Dis Child 1987;62: 529-38.

2 Reynolds EOR. Effects of alterations in mechanical ventilator settings on pulmonary gas exchange in hyaline membrane disease. Arch Dis Child 1971;46:152-9.

${ }^{3}$ Herman S, Reynolds EOR. Methods of improving oxygenation - in infants mechanically ventilated for severe hyaline membrane disease. Arch Dis Child 1973;48:612-6.

${ }^{4}$ Greenough A, Milner AD. High frequency ventilation in the neonatal period. Eur J Pediatr 1987;146:446-9.

5 Field DS, Milner AD, Hopkin IE, Madeley RJ. Changing patterns of neonatal respiratory distress. Pediatr Pulmonol 1987;3:231-5.

6 Greenough A, Greenall F. Performance of respirators at fast rates commonly used in neonatal intensive care. Pediatr Pulmonol 1987;3:357-61.

${ }^{7}$ Heicher DA, Kasting DS, Richards JR. Prospective clinical comparison of two methods for mechanical ventilation of neonates: rapid rates and short inspiratory time versus slow rate and long inspiratory time. J Pediatr 1981;98:957-81.

8 Pohlandt F, Bernsau V, Feilen KD, et al. Reduction of barotrauma in ventilated neonates by increase in ventilation frequency. First results of a prospective colaborative and randomised trial of two different ventilatory techniques. Pediatr Res 1985;19:1077.

9 Greenough A, Wood S, Morely CJ, Davis JA. Pancuronium prevents pneumothoraces in ventilated premature babies who actively expire against positive pressure ventilation. Lancet $1984 ;$;: $1-4$.

10 Field DJ, Milner AD, Hopkin IE. Manipulation of ventilator settings to prevent active expiration against positive pressure inflation. Arch Dis Child 1985;60:1036-40.

1 Greenough A, Morley CJ, Pool J. Fighting the ventilator-are fast rates an effective alternative to paralysis? Early Hum Dev 1986;13:189-94.

12 Field DJ, Milner AD, Hopkin IE. High and conventional rates of positive pressure ventilation. Arch Dis Child 1984;59:115-8.

13 Greenough A, Pool J, Greenall F, Morley C, Gamsu H. Comparison of different rates of artificial ventilation in preterm neonates with the respiratory distress syndrome. Acta Paediatr Scand 1987;76:706-12.

${ }^{14}$ Froese AB, Bryan AC. High frequency ventilation. Am Rev Respir Dis 1987;135:1363-74.

15 Carlo WA, Chatburn RL, Martin RJ. Decrease in airway pressure during high frequency jet ventilation in infants with respiratory distress syndrome. J Pediatr 1984;104:101-7.

16 Pokora T, Bing D, Mammel M. Neonatal high frequency jet ventilation. Pediatrics 1983;72:27-32.

17 Mammel MC, Boros SJ. Airway damage and mechanical ventilation. Pediatr Pulmonol 1987;3:443-7.

18 Metlay LA, MacPherson TA, Doshi N, Milley JR. A new iatrogenous lesion in newborns requiring assisted ventilation. N Engl J Med 1983;309:111-2.

19 Harris TR, Chistensen RD. High frequency jet ventilation treatment of pneumonous interstitial emphysema. Pediatr Res 1984;19:3264.

${ }^{20}$ Frantz ID III, Werthammer J, Stark AR. High frequency ventilation in premature infants with lung disease: adequate gas exchange at low tracheal pressure. Pediatrics 1983;71:483-8.

21 Gaylord MS, Quissell BH, Lair ME. High frequency ventilation in the treatment of infants weighing less than $1500 \mathrm{gms}$ with pulmonary interstitial emphysema. Pediatrics 1987;79:915-21.

22 Hoskyns EW, Milner AD, Hopkin IE. Oscillating volumes during ventilation with high frequency oscillation. Early Hum Dev 1988;17:96.

23 Chang HK. Mechanisms of gas transport during ventilation by high frequency oscillation. J Appl Physiol 1984;56:553-63.

${ }^{24}$ Hoskyns EW, Milner AD, Hopkin IE. Dynamic lung inflation during high frequency oscillation in respiratory distress syndrome. Early Hum Dev 1987;15:186-7.

25 DeLemos RA, Gerstmann DR, Clark RH, Guajardo A, Null DM. High frequency ventilation-the relationship between ventilator design and clinical strategy in the treatment of hyaline membrane disease and its complications: a brief review. Pediatr Pulmonol 1987;3:370-2.

26 Bryan AC, Slutsky AS. Lung volume during high frequency ventilation. Am Rev Respir Dis 1986;133:928-30.

A D Milner and E W Hoskyns Department of Neonatal Medicine and Surgery, City Hospital, Nottingham NG5 1PB. 